\title{
Estudo anatômico e palinológico de Antônia ovata Pohl (Loganiaceae)
}

\author{
José ELIAS DE PAULA \\ Departamento de Biologia Vegetal, \\ Universidade de Brasília
}

\section{SINOPSE}

Nesta comunicação o autor considera a anatomia do caule, pecíolo, lâmina foliar e madeira, além dos aspectos morfológicos externo e palinológico, de es. pécimes de Antonia ovata, ocorrentes na floresta da região do rio Jarí (Estado do Pará) e nos cerrados da Amazônia e do Brasil Central; nomeia os espéci. mes da mata como sendo uma variedade nova para a ciência: Antonia ovata Pohl var. excelsa Paula.

\section{INTRODUÇão}

O gênero Antonia é monotípico, portanto isolado. Ocorre nos cerrados da Amazônia e extra-amazônicos, notadamente no Brasil Central. Ultimamente, foram coletados espécimes de Antonia, em matas altas da terra firme, na região do rio Jarí (Estado do Pará). Êsses espécimes são árvores grossas de até $1 \mathrm{~m}$ de diametro e de 25 a $30 \mathrm{~m}$ de altura, enquanto que os espécimes dos cerrados são arbustos ou árvores finas de $4-10 \times 0,05$ a $0,08 \mathrm{~m}$. Os indivíduos da regiāo do rio Jarí foram identificados por $\mathrm{J}$. Murça Pires (1968), como sendo Antonia ovata Pohl. A identificação foi baseada na morfologia externa da planta, sendo mínimas as diferenças na morfologia externa, entre os espécimes da região do rio Jarí e os dos cerrados. Por isso pensamos que se tratasse de um ecotipo ou até mesmo de uma nova espécie, que constituiria, com Antonia ovata, um par vicariante. Daí, a idéia de estudarmos a anatomia e os grãos de pólen, cujo trabalho nos propusemos realizar, estudando, comparativamente, os espécimes dos três habitats, partindo da análi se da morfologia externa.

\section{MATERIAL}

Nomeamos a seguir os espécimes estudados, indicando nomes de coletores, local e data de coleta e referência de herbário onde eles estão depositados:

1 - Antonia ovata Pohl var. ovata (Progel) Paula

a) Coletor: Irwin, J. W. Grear Jr. 16141(UB); local de coleta: Xavantina, cerrado, Estado de Goiás, em 27-5-1966; determinador: J. M. Pires.

b) Coletor: Prance et Silva 58450(UB); loca! de coleta: Miracema, cerrado, Goiás, em 28-7-1964; determinador: Prance.

c) Coletor: J. Elias de Paula 516(UB); local de coleta: estrada Sobradinho-Formosa, 3,1 $\mathrm{Km}$ depois da ponte Pipiripipau, cerrado, Goiás, em 12-7-1971; determinador: J. Elias de Paula.

d) Coletor: J. Elias de Paula 517(UB); local de coleta: estrada Sobradinho-Formosa, cerrado, Goiás, em 12-7-1971; determinador: J. Elias de Paula.

2 - Antonia ovata Pohl vol. pilosa (Hook) Progel

a) Coletor: Saccard 266 (INPA e UB); local de coleta: Normanda, cerrado, base da serra, Território do Rio Branco, em 23-10-1954; determinador: J. M. Pires.

b) Coletor: Irwin et Soderstrom 5954 (UB). local de coleta: Parque do Gama, D. F., cerrado, em 4-9-1964; determinador: J. M. Pires.

c) Coletor: Black, Silva, Egler et P. Cavalcante 57-19703(UB); local de coleta: Ariramba, cerrado, Estado do Pará, em 28-5-1957; determinador: J. M. Pires.

d) Coletor: Hunt 5741(UB); local de coleta: Xavantina, cerrado, Goiás, em 2-6-1966; determinador: J. M. Pires. 
e) Coletor: M. Magalhães 19499(UB); local de coleta: Santa Vitória, cerrado, Minas Gerais, em 5-1963; determinador: J. M. Pires.

f) Coletor: J. Elias de Paula 519(UB); local de coleta: estrada Sobradinho-Formosa, 3,1 $\mathrm{Km}$ depois da ponte Pipiripipau, cerrado, Goiás; determinador: J. Elias de Paula.

g) Coletor: Black 13763(IAN); local de coleta : cerrado da Amazônia; determinador: J. M. Pires.

3 - Antonia ovata Pohl var. excelsa Paula, n. var.

a) Coletor: E. Oliveira 4806(IAN); local de coleta: Planalto do Monte Dourado, Estado do Pará, mata da terra firme, rio Jarí, em 29-8-1968; determinador: J. M. Pires; árvore de $25 \mathrm{~m}$ de altura.

b) Coletor: E. Oliveira 4817(IAN); local de coleta : Planalto do Monte Dourado, mata alta da terra firme, rio Jarí, Estado do Pará, em 31-8-1968; determinador: J. M. Pires.

c) Coletor: N. T. Silva 2864(IAN); local de coleta: rio Jarí; determinador: J. M. Pires.

d) Coletor: J. M. Pires 511(IAN); local de coleta: rio Jarí; determinador: J. M. Pires.

\section{MÉtodo}

Para o estudo dos grãos de pólen utilizamos a técnica de acetólise (Erdtman 1966; Salgado-Labouriau 1961 e 1966). Para o estudo da anatomia do pecíolo os cortes foram praticados na porção média. Com relação ao estudo do lenho secundário, os cortes histológicos foram realizados através do micrótomo para madeira de "Jung". Os grãos de amilo foram identificados, por apresentarem coloração roxo-azula. do na presença do Lugol, e também sob luz polarizada, de cujo efeito resulta uma zona escura: denominada "Cruz de Malta". As fotomicrografias foram obtidas através do Fotomicroscópio "Wild".

\section{RESULTADOS}

\section{A". MORFOLOGIA EXTERNA}

Antonia ovata Pohl (PI. Brasil., 2: 13, t. 109. 1828/29; Progel, 1860/68, FI. Bras., 6(1): 251). Antonia pubescens (Boor, Mem. Acad. Petro.,
Ser. 6(3): 2, t. 1, em Progel, 1c.). Antonia pilosa (Hook, Pl. Bras., 2: 13, t. 64, em Progel, 1c.; Condolle, 1845, Prodromus, 9: 20-21).

Arbusto ou árvoré de até $30 \mathrm{~m}$ de altura; madeira leve, com casca fina; ramos, folhas e pedúnculo da inflorescência glabros ou pilosos; folhas opostas, pecíolo com 0,5 a $1,5 \mathrm{~cm}$ de comprimento, canaliculado; lâmina foliar glabra ou pilosa, ovada ou ovado-elíptica, com $3 \times 2,5$ a $8 \times 5 \mathrm{~cm}$, nervação secundária camptodroma; inflorescência corimbo, terminal; botões florais amarelados; flores em plena antese alvas, odoríferas; cálice com 5 sépalas imbricadas, com bordos pilosos, protegidos por várias brácteas imbricadas, ecamosas; corola com 5 pétalas unidas na base, com pelos nos bordos; antese reflexa; tubo da corola piloso, internamente, na porção superior; antera biloculada, com deiscência lateral, dorsifixa (versátil); estames 5, epipétalos, glabros, com cerca de $1 \mathrm{~cm}$ de comprimento; ovário bilocular, ovóide, quase glabro, com 2 óvulos; estígma sub-bilobado, papilosos; estilete glabro, com cerca de $1 \mathrm{~cm}$ de comprimento grāos de pólen 3-colporados, subreticulados, de forma variada, sendo mals irequente oblato-esferoidal e subprolato, diâmetro poiar entre 16 e 19 micra, diametro equatoriai entre 14 e 22 micra; fruto cápsula, geralmente cilíndrica, com $1 \mathrm{~cm}$ de comprimento por $1 \mathrm{~mm}$ de diametro, bivalvar, glabro; semente 1-2, por fruto, oblonga, albuminada, com $1-2 \mathrm{~mm}$ de comprimento por $1 \mathrm{~mm}$ de largura; tegumento seminal com cerca de 40 micra de espessura, rico em esclerenquima, epiderme externa pilosa.

Antonia ovata Pohl var. ovata (Progel) Paula; A. ovata Pohl var. glabra Progel. Arbusto ou árvore de 4 a $8 \mathrm{~m}$ de altura; ramos, folhas e pedúnculo da inflorescência glabros, às vezes ocorrem pelos apenas no nó foliar e ao longo das nervuras secundárias, muito esparsamente; grãos de pólen oblato-esferoidal em vista equatorial ( $\left.\frac{P}{E} \cdot 100=90\right)$; mas ocorrem também grãos de pólen tipicamente prolato $\left(\frac{P}{E} \cdot 100=140\right)$ e prolato esferoidal $\left(\frac{\bar{P}}{\mathrm{E}} \cdot 100=101\right)$, diâmetro polar 19,4 micra em média, variando entre $16 \mathrm{e}$ 22,4, diâmetro equatorial 19,7 micra, em média, variando entre 16 e 22,4; semicircular em vista polar, com 19,6 micra de diâmetro mediano, em 

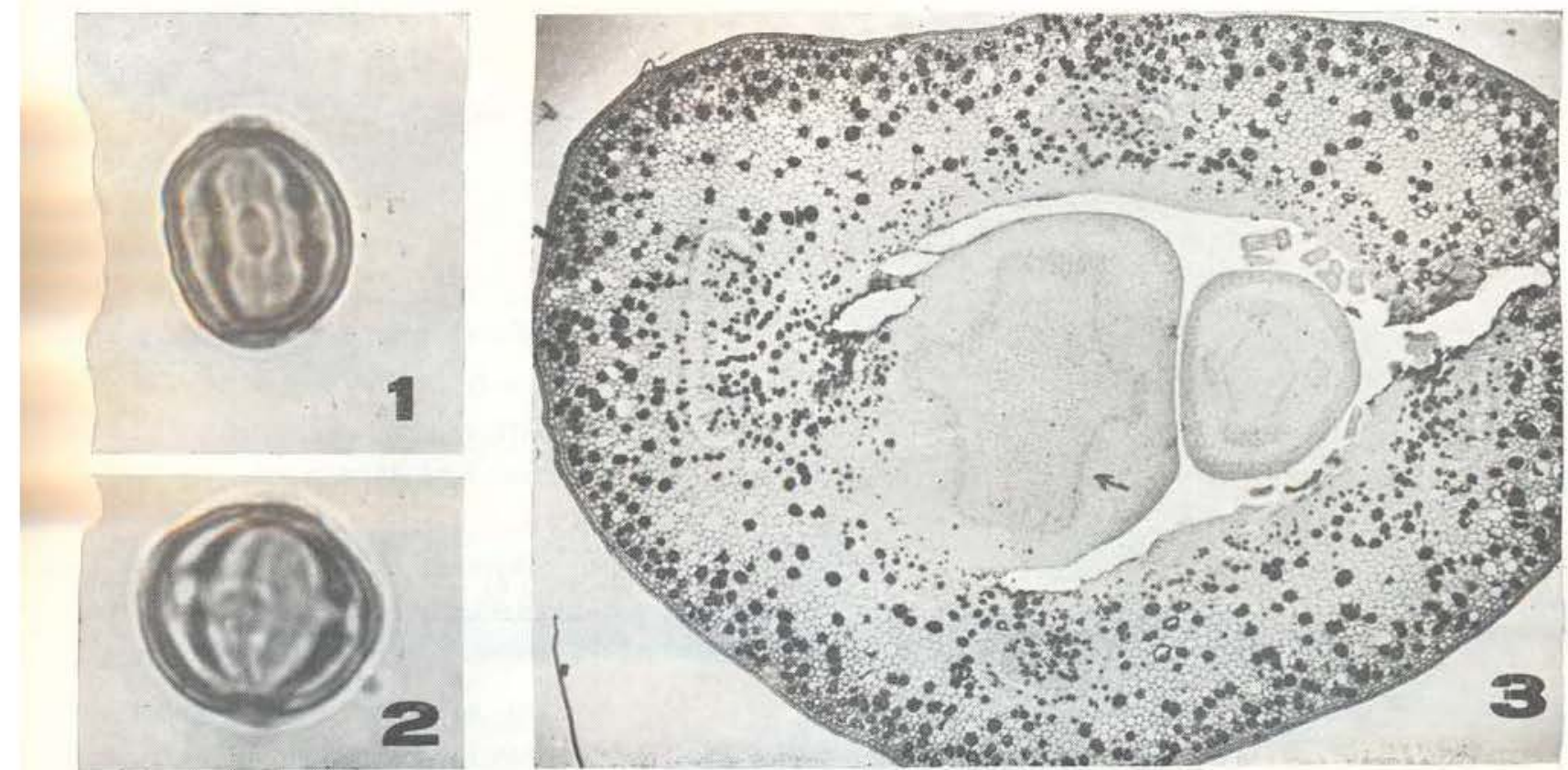

Foto 1) - A, ovata var. Excelsa - Grão de pólen em vista equatorial (780X). Foto 2) - A ovata var. pilosa - Gräo de pólen em vista equatorial $(780 \mathrm{X})$. Foto 3$)-A$. ovata var. ovata - Secção transversal do broto apical do ramo, onde se vêem cordões vasculares do rastro foliar (86X)
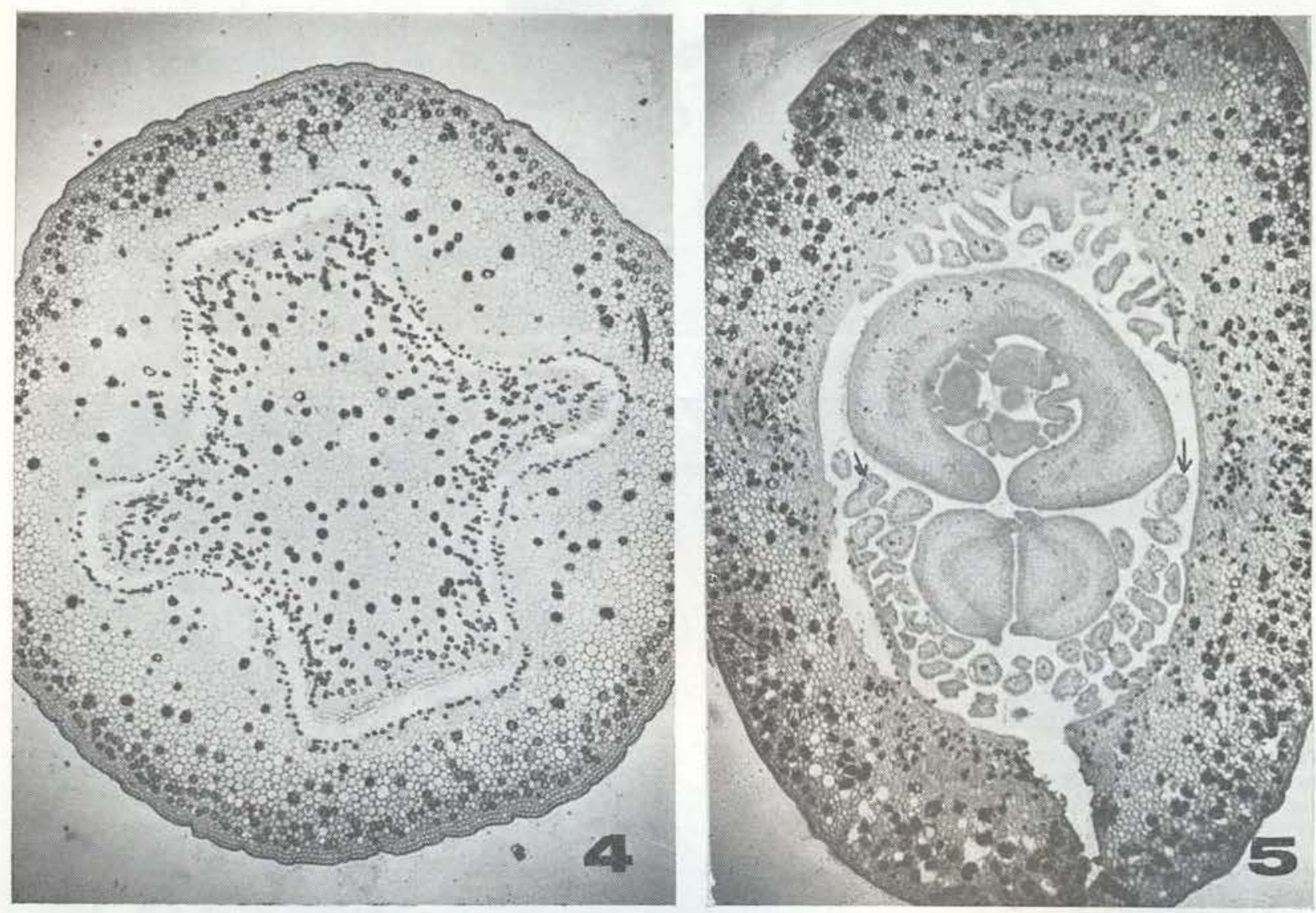

Foto 4) - A. ovata var, ovata - Nó foliar, mostrando a evolução do rastro foliar; bainha amilífera pericíclica $(86 \mathrm{X})$. Foto 5) $-A$, ovata var. ovata - Corte transversal do broto apical ao nível de nectários extra-florais. onde se vêem "pitélios" de revestimento (86X) 


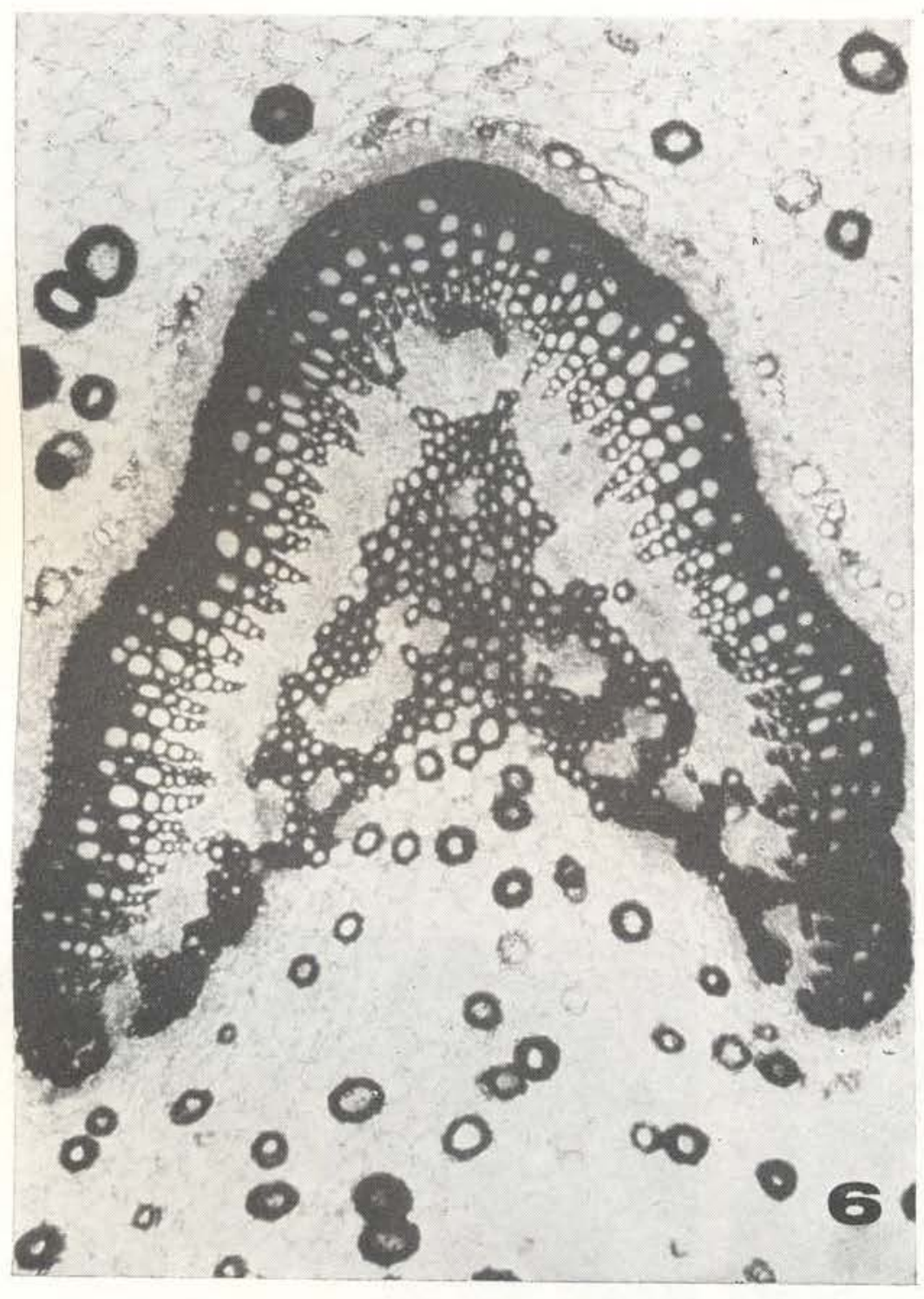

Foto 6) $-A$, ovata var. excelsa $-\mathrm{Pe}-$ cíolo: corte transversal da porção média (100X)

Foto 7) - A. ovata var. ovata Corte transversal de um broto apical onde se vêem primórdios foliares e vesiculares nectarianos $(138 \mathrm{X})$.

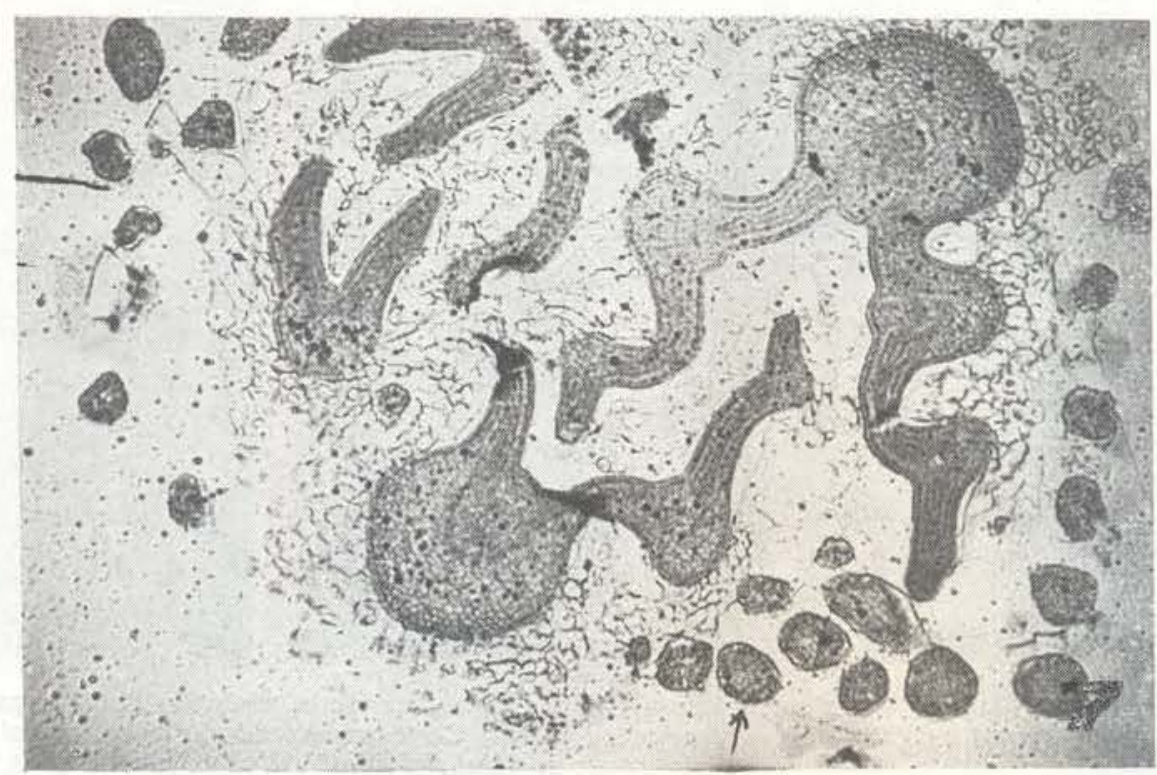


média, variando entre 17,6 e 22,4; colpori 3, com margem; os circular, com margem (Fig. 2: $b$ e c). Madeira leve (Fig. 2, b-c).

Antonia ovata Pohl var. pilosa (Hook) Progel; A. pilosa Hook; A. pubescens Borg. Arbusto ou árvore de 4 a $10 \mathrm{~m}$ de altura; folhas, ramos e pedúnculo da inflorescência pilosos; madeira leve: grãos de pólen subreticulados, subprolato em vista equatorial ( $\frac{P}{E} \cdot 100=118$ ), diâmetro polar 17 micra, em média, variando entre $16 \mathrm{e}$ 19, diâmetro equatorial 14,4 micra, em média, variando entre 14 e 16 , semicircular em vista polar, com 19 micra de diâmetro median’, em média, variando entre 17,6 e 20,8 ; colpori 3 , com margem; os circular, com margem. (Foto 2).

Antonia ovata Pohl var. excelsa Paula, n. var. Árvore grossa, mais ou menos $1 \mathrm{~m}$ de diâmetro e de até $30 \mathrm{~m}$ de altura; folhas quase glabras; ramos e pedúnculo da inflorescência pilosos; madeira leve; grãos de pólen subreticulados, prolato-esferoidal em vista equatorial $\left(\frac{P}{E} \cdot 100=100\right)$, mas ocorrem também grãos de pólen tipicamente prolato $\left({ }_{\mathrm{E}}^{\mathrm{P}} \cdot 100=144\right)$; diâmetro polar 17,8 micra, em média, variando entre 16 e 19; semicircular em vista polar, com 16,6 micra diâmetro mediano, em média, variando entre 16 e 19; colpori 3, com margem; os subcircular, com tendência a "lolongate" (Foto 1; fig. 1-c e fig. 2-d).

\section{B. MADEIRA}

\section{Antonia ovata var. ovata}

Caracteres gerais: madeira leve, peso específico entre 0,45 e $0,50 / \mathrm{cm}^{3}$, em amostras secas ao ar (de Brasilia, DF., mês de Junho); casca fina, um pouco áspera; alburno indistinto de cerne, de cor cinza-claro; grã fina, regular; textura média; apresenta fluorescência azul celeste quando iluminada por luz ultra-violeta de ondas longas.

Caracteres macroscópicos: poros indistintos a olho nu; linhas vasculares visíveis com auxílio de lente $(10 x)$, estreitas, geralmente longas; parênquima ausente; raios de topo finos, visiveis com aumente de 12x; camadas de crescimento bem características (Fotos 20 e 12).
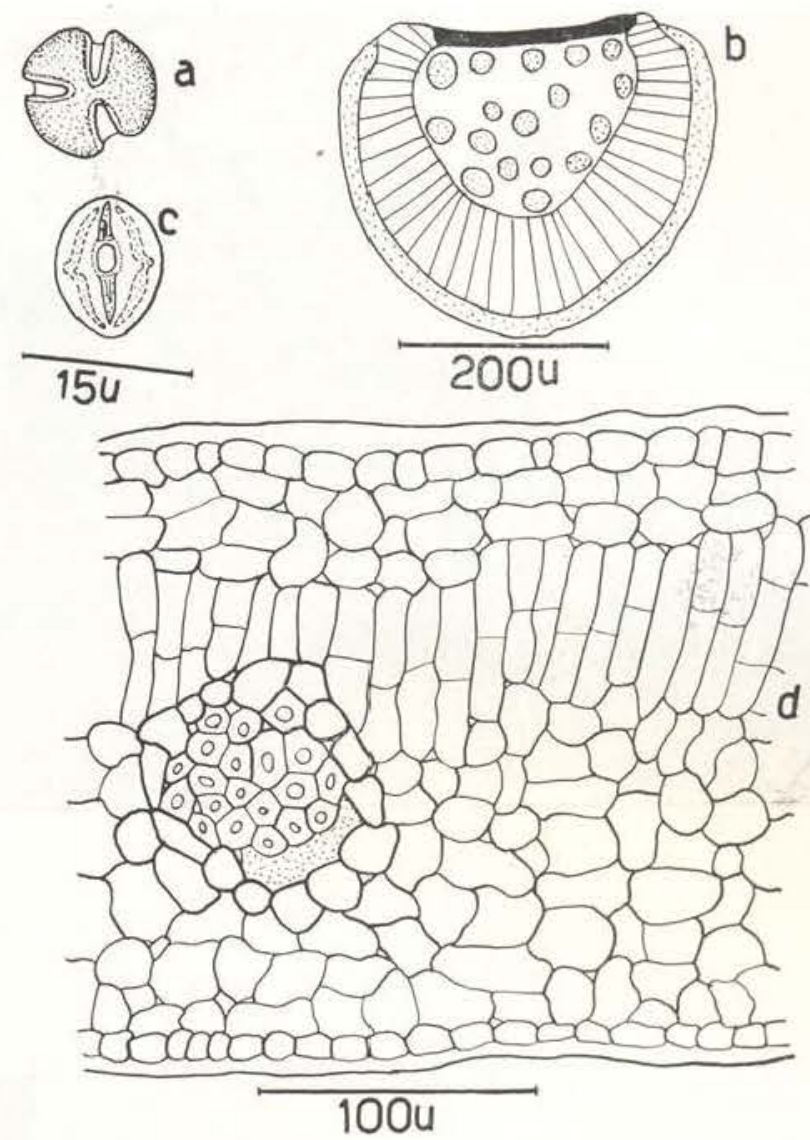

Fig. 1 - a) var. excelsa: grão de pólen em vista polar: b) sistema vascular da nervura central; c) grão de pólen em vista equatorial (prolato); d) lâmina foliar em secção transversal, onde se vêem hipoderme, feixes vasculares envolvidos por uma bainha de células de paredes moderadamente espessas e células paliçádicas divididas (divisão tardia)

Caracteres microscópicos - Poros: distribuição moderadamente regular, de secção ovóide, semicircular ou irregular; predominantemente múltiplos aglomerados ou em séries radiais regulares ou irregulares de até 9 elementos: muito numerosos, 30 por $\mathrm{mm}^{2}$ em média, variando entre 26 e 33 , sendo $60 \%$ entre 29 e 33 ; pequenos, 65 micra de diametro radial em média, variando entre 18 e 122 , sendo $45 \%$ entre 64 e 96 . Elementos vasculares curtos, $0.56 \mathrm{~mm}$ de comprimento em média, variando entre $0,3 \mathrm{e}$ $0,56 \mathrm{~mm}$; área de perfuração simples, parcial; pontuações intervasculares pequenas, guarnecidas, alternas, de contorno eliptico; pares de pontuações areolados; pontuações raido-vasculares semelhantes às intervasculares, pares de pontuações alternos, semiareolados. Fibrotraqueoides escassos. Raios unisseriados, às vezes multisseriados, com 2-3 células de largura: 


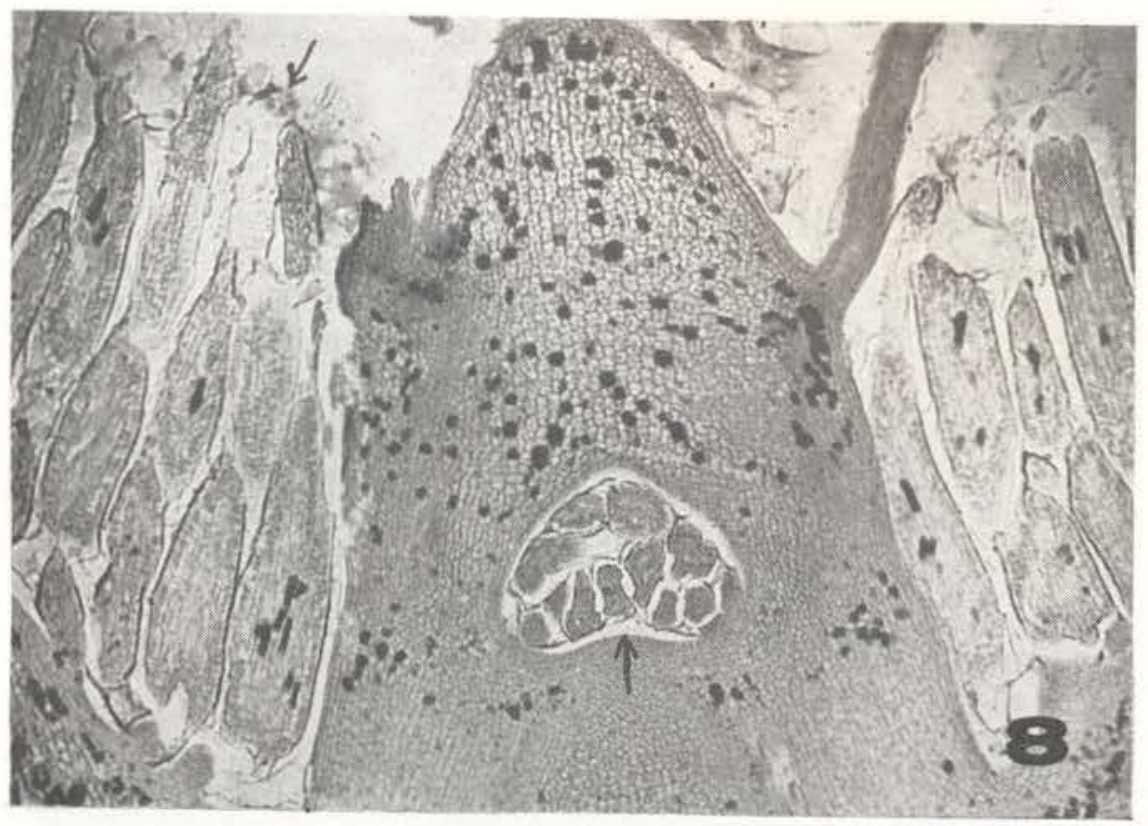

Foto 8) - A. ovata var, ovata Corte tangencial de um broto apical onde se vêem partes de nectários extraflorais $(138 \mathrm{X})$.
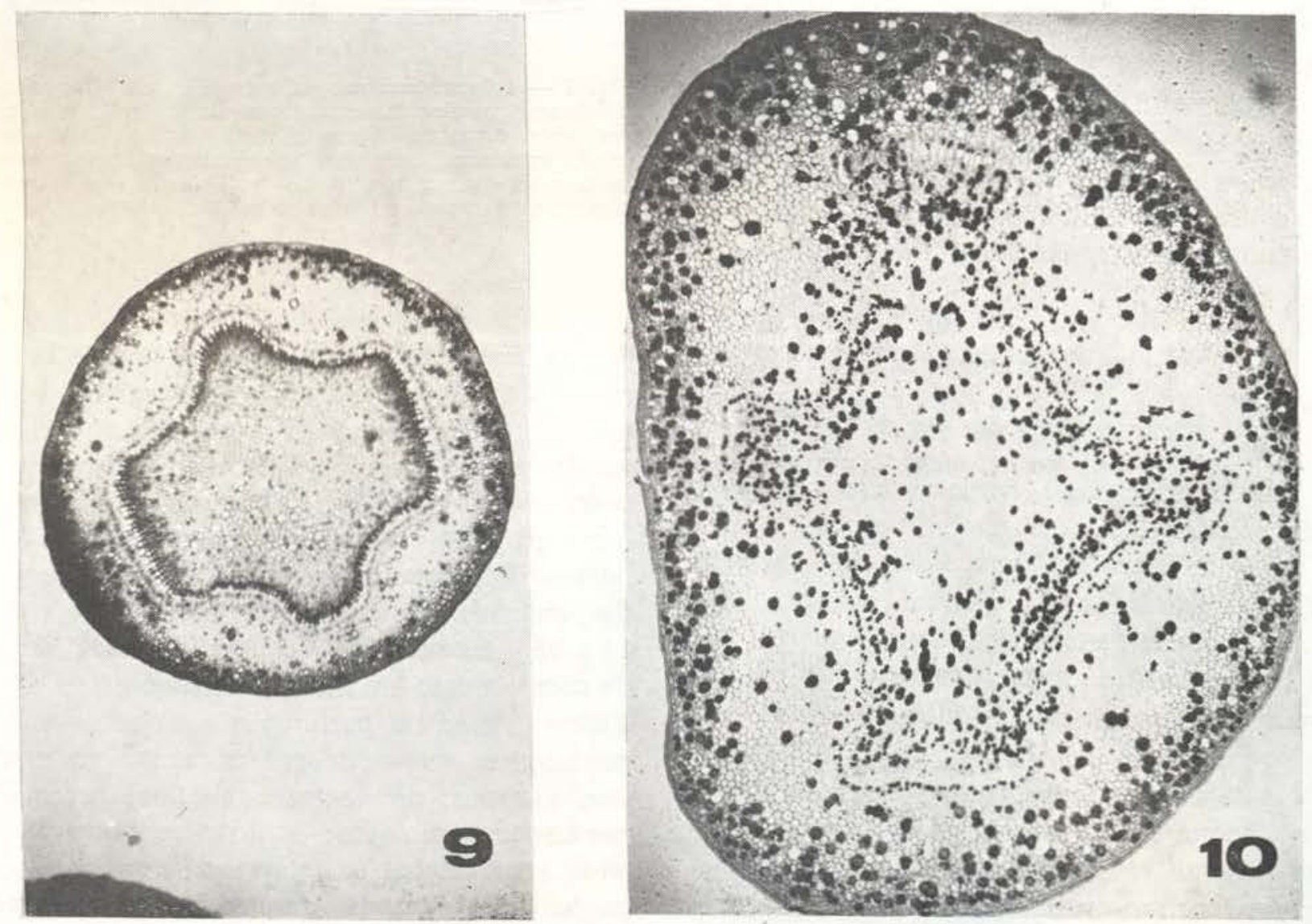

Foto 9) - A. ovata var, ovata - Estrutura primária do caule, onde se observa uma bainha amilífera pericíclica $(86 \mathrm{X})$. Foto 10$)-A$. ovata var. ovata - Nó foliar, mostrando a evolução do rastro foliar; bainha amilífera pericíclica $(86 \mathrm{X})$. 
muito numerosos, 14 por $\mathrm{mm}$ em média, variando entre 12 e 16 , sendo $70 \%$ entre 13 e 16; extremamente baixos, 140 micra de altura em média, variando entre 48 e 278 , sendo $40 \%$ entre 128 e 176; 7 células em altura em média, variando entre 2 e 20 , sendo $50 \%$ entre 5 e 10; os raios multisseriados são extremamente baixos, entre 129 e 134 micra de altura; muito estreitos. entre 16 e 26 micra de largura; nos multisseriados ocorrem cordões de floema. Parenquima axial: em geral ausente, raramente aparecendo pequenos grupos de células de parenquima desse tipo contíguos aos vasos. Fibras: abundantes, muito delgadas, com lúmem correspondendo a cerca de $3 / 4$ do diâmetro total da fibra; pontuações areoladas, às vezes simples, lineares, pequenas; elementos fibrosos muito curtos, $0,9 \mathrm{~mm}$ de comprimento em média, variando entre 0,7 e $1 \mathrm{~mm}$, raramente 1,4 , sendo $56 \%$ entre 0,8 e $0,96 \mathrm{~mm}$. Floema incluso (interxilar) : moderadamente abundante, 5 cordōes de floema por $\mathrm{mm}^{2}$ em média, variando entre 2 e 7 , sendo
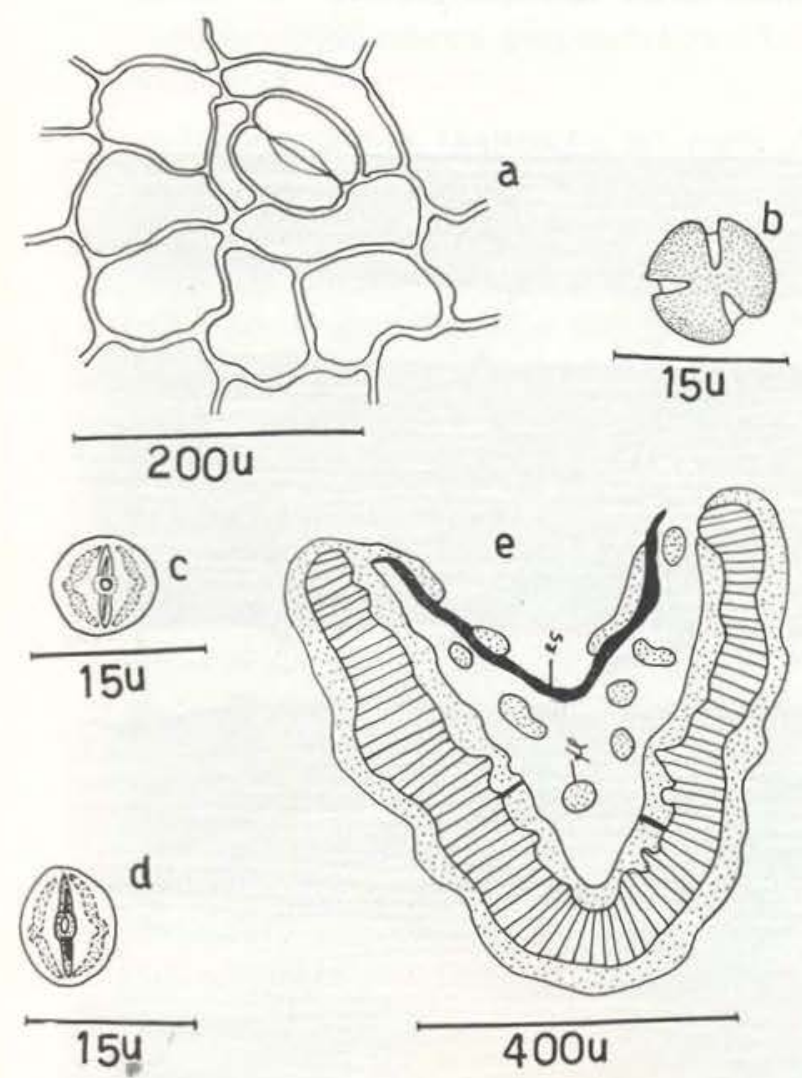

Fig, 2 - a) var, pilosa: epiderme abaxial; b) var. ovata: grâo de pólen em vista polar; c) var. ovata : grâo de pólen em vista equatorial; d) var. excelsa : grão de pólen em vista equatorial (prolato-esferoidal): e) var, ovato: sistema vascular da porção média do pecíolo ( $f l$, flomea; es, esclerênquima)
$60 \%$ entre 5 e 7 ; em secção transversal os cordões de floema aparecem sob forma mais ou menos circular ou tangencialmente alongada. Camadas de crescimento: nitidamente visiveis. pelo achatamento tangencial das fibras do lenho tardio, que constituem os limites entre as camadas de crescimento (Fotos 18 e 19).

\section{Antonia ovata Pohl var. pilosa}

Madeira leve, peso específico entre 0,65/ $\mathrm{cm}^{3}$ e $0,68 / \mathrm{cm}^{3}$, em amostras secas nas mesmas condições da variedade anterior; casca fina, lisa, quase negra quando seca; alburno de côr cinza, indistinto do cerne; grä fina, regular; textura média; poros indistintos a olho nu; linhas vasculares visíveis com aumento de 10x, geralmente longas; raios de topo finos, visiveis com aumento de $12 x$; parênquima ausente; camadas de crescimento bastante típicas, bem visíveis; apresenta fluorescência azul celeste. Quanto aos caracteres anatômicos e numéricos dos elementos componentes do lenho secundário, salientamos apenas as diferenças entre esta variedade e a anterior (vide quadro) (Fotos 23 e 11).

\section{Antonia ovata Pohl var. exceisa}

Madeira leve, peso específico entre 0,50 e $0,60 / \mathrm{cm}^{3}$, em amostras secas nas mesmas condições das variedades anteriores; casca fina, lisa; alburno indistinto do cerne, de cor bege; grã fina, regular; textura média; poros indistintos a olho nu; linhas vasculares visiveis com aumento de $10 x$, geralmente longas; parênquima axial ausente; camadas de crescimento pouco típicas, às vezes indistintas; não apresenta fluorescência na presença de luz ultra-violeta. Quanto aos caracteres anatômicos e numéricos dos elementos componentes do lenho secundário, salientamos apenas as diferenças entre esta variedade $\mathrm{e}$ as duas anteriores (vide quadro) (Fotos 20 e 13).

\section{CAULE}

Considerando que a estrutura anatômica das três variedades em apreço é muito semeIhante, tomamos por base para a nossa descrição a variedade ovata salientando apenas diferenças no decurso da descrição e no capítulo de Discussão. 

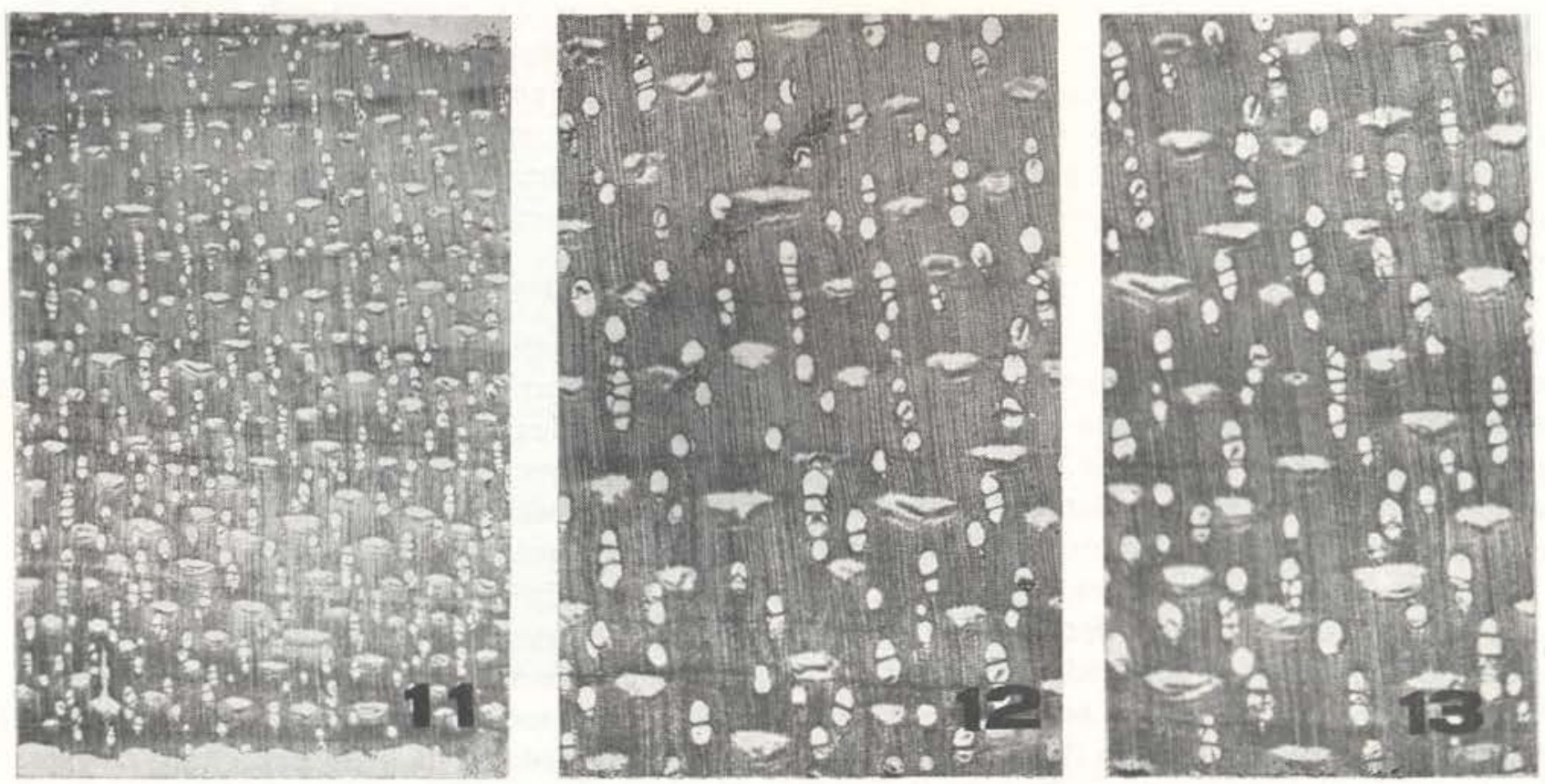

Foto 11) - A, ovata var, pilosa - Madeira: secção transversal, onde se vêem camadas de crescimento (12X) Foto 12) - A. ovata var, ovata - Madeira : secção transversal, onde se vêem camadas de crescimento (12X). Foto 13) - A. ovata var. excelsa - Madeira : secção transversal (12X).

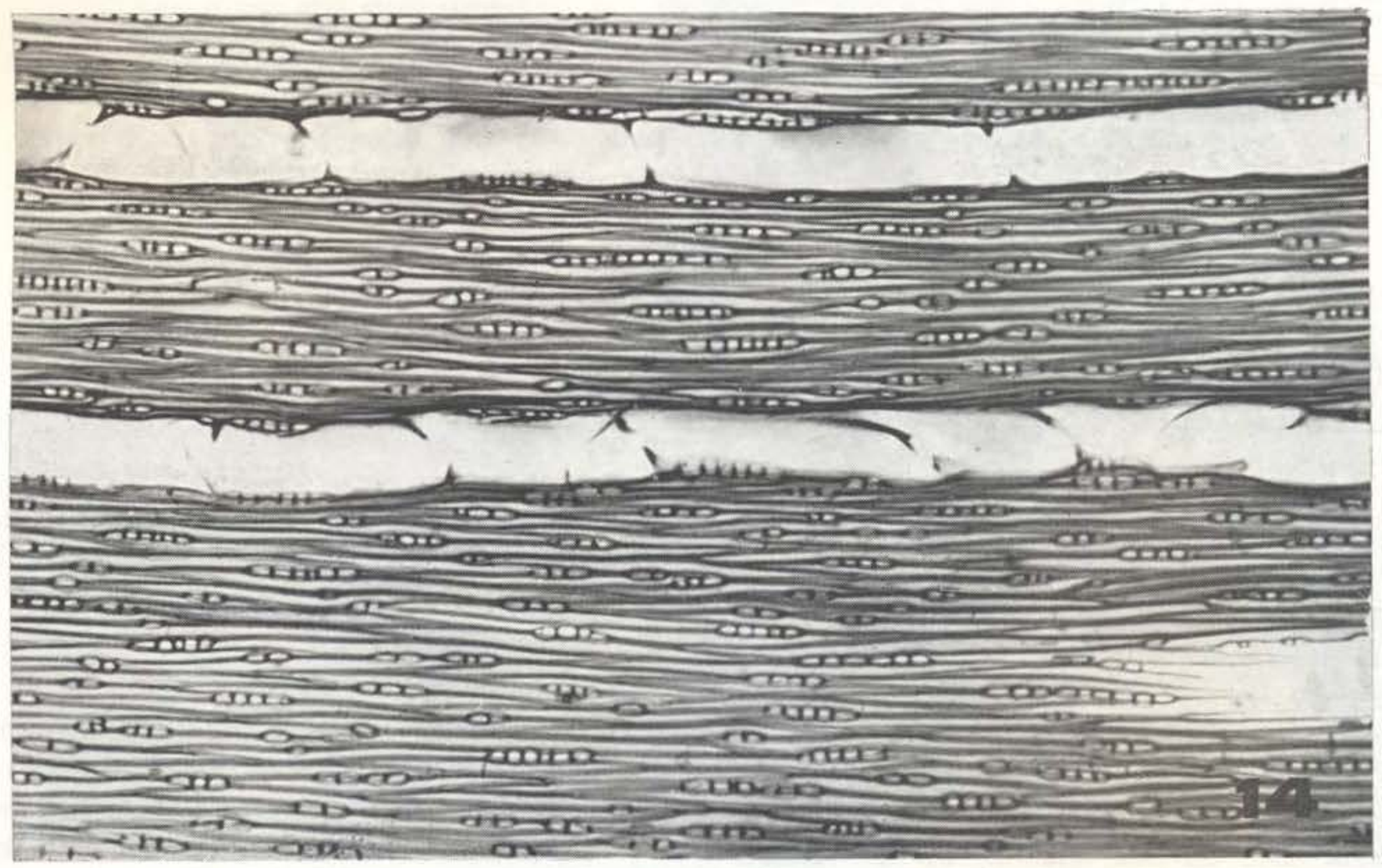

Foto 14) - A. ovata var. pilosa - Madeira : secção tangencial (100X). 
Estrutura primária indiferenciada (meristema primário). Nesta fase de diferenciação, na direção periferia-centro observamos as seguintes camadas: a) "protoderme" — as células protodérmicas, vistas em secção transversal, realizada em brotos apicais de ramos, habitualmente apresentam forma retangular, com maior diâmetro periclinal, paredes pectocelulósicas e núcleos grandes, semiesféricos. b) "parenquima fundamental cortical" - constituído de células moderadamente pequenas de forma e tamanho variáveis, com paredes pectocelulósicas. ricas em proplastídios onde se observam pequenos gräos de amilo; entre essas células ocorrem idioblastos mucilaginosos. c) "procâmbio" Nesta fase já se distingue este meristema com facilidade, pois, seus elementos são bem menores que os do parênquima fundamental, com núcleos grandes e citoplasma bastante denso; o procâmbio visto em cortes transversais tem forma de "Cruz de Malta". d) "Parênquima fundamental medular" - E constituido de células semeihantes às do parênquima fundamental cortical, porém com menos proplastídios. (Fotos $3,4,5$ e 7 ).

Examinando cortes realizados ao nivel do nó foliar, na base do pecíolo e no próprio nó, observamos formações secretoras, situadas em depressōes revestidas de "epitélios" alongados-paliçádicos, pluricelulares e que se comunicam com a exterior por meio de um pequeno orifício. Essas formações secretoras são nectários extra-florais (Fotos 5 e 8).

Estrutura primária diferenciada - Epiderme glabra, sendo porém pilosa nas variedades pilosa e excelsa; pelos unisseriados, pluricelulares; em secção transversal as células epidémicas são retangulares com maior diâmetro periclinal, às vezes na anticlinal por divisão anticlinal de células protedérmicas; cutícula fina. uniforme. Colênquima do tipo lamelar (observado em material fresco), com células ricas em grãos de amilo, que constituem 3-4 camadas; entre tais células ocorrem idioblastos taníferos e mucilaginosos. Parênquima cortical constituído de células relativamente grandes de forma e tamanho variados, com núcleos e nucléolos bem visiveis; paredes finas, pectocelulósicas, deixando entre si, nos ângulos, pequenos meatos. Esse parênquima é rico em células muci- laginosas, notadamente na porção externa e em idioblastos contendo drusas de oxalato de cálcio. Na região pericíclica há uma bainha amilifera (Fotos 4 e 9).

Sistema vascular - os feixes vasculares são bicolaterais, ocorrendo também cordões de floema perimedulares. A região vascular, vista em secção transversal, tem forma semelhante a da "Cruz de Malta"; entre as células parenquimatosas da região do floema ocorrem e!ementos taníferos e mucilaginosos; os vasos lenhosos estão distribuídos em séries radiais de 4 a 7 elementos, separados pelos raios 1 - 2 seriados; são freqüentes elementos do protoxilema completamente obliterados. A medula apresenta estrutura semelhante à do parênquima cortical.

Rastro foliar. Analisando cortes do nó foliar, obtidos em séries da base para o ápice, constatamos que o rastro foliar é constituído de dois feixes vasculares assimétricos, cada um deixando uma lacuna (Fotos 4 e 10).

Estrutura secundária. O felogênio de origem subepidérmica produz mais feloderma do que súber. O súber consta de somente um tipo de células: as tipicamente suberosas $(2 \cdot 3$ camadas de células) com paredes finas totalmente suberizadas; raramente aparecem células com paredes finas lignificadas. No início da estrutura secundária começam a se constituir. no córtex, numerosos esclerócitos, notadamente ao nível do nó foliar; no córtex ocorrem também células taníferas e mucilaginosas. Nesta fase de diferenciação, a estrutura anômala já é evidente, caracterizada pela presença de numerosos cordōes de floema incluso no lenho. No lenho nota-se a ausência de parenquima axial. Os raios são unisseriados. As fibras são abundantes; os vasos são múltiplos radiais, cujos elementos traqueais possuem perfuraçōes simples, parciais, na maioria dos casos. As células medulares já estão com paredes lignificadas, algumas delas espessas; na região perimedular ocorrem cordões de floema.

\section{FOLHAS}

a) Peciolo - Epiderme pilosa ou quase glabra; tricomas simples, unicelulares. São freqüentes elementos esclerosados na parênquima 

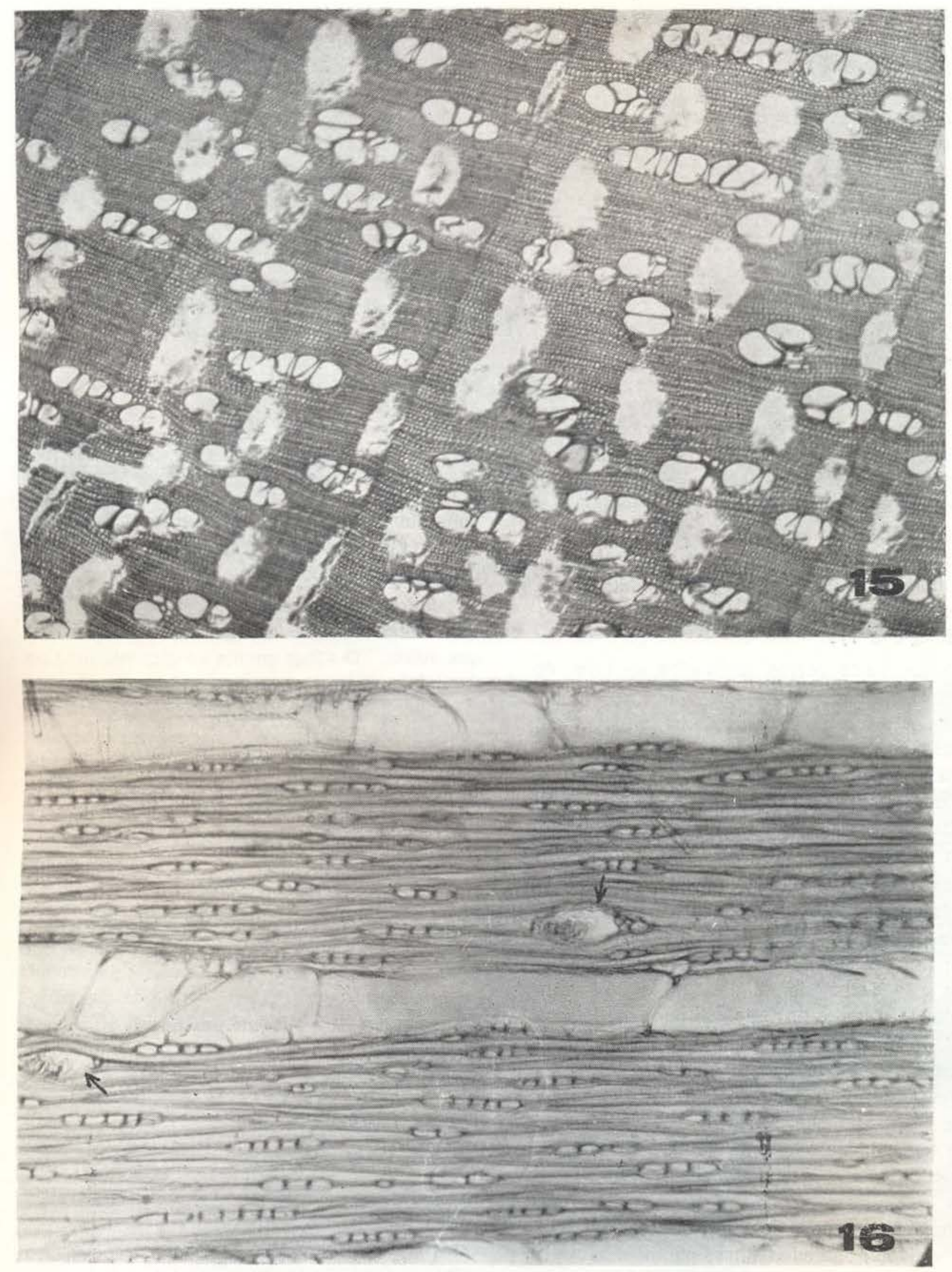

Foto 15) - A. ovata var. pilosa - Madeira : secção tangencial (100X). Foto 16) - A. ovata var. excelsa - Madeira: seç̧âo tangencial, onde se vêem 2 cordões de floema radial e 2 vasos (100X). 

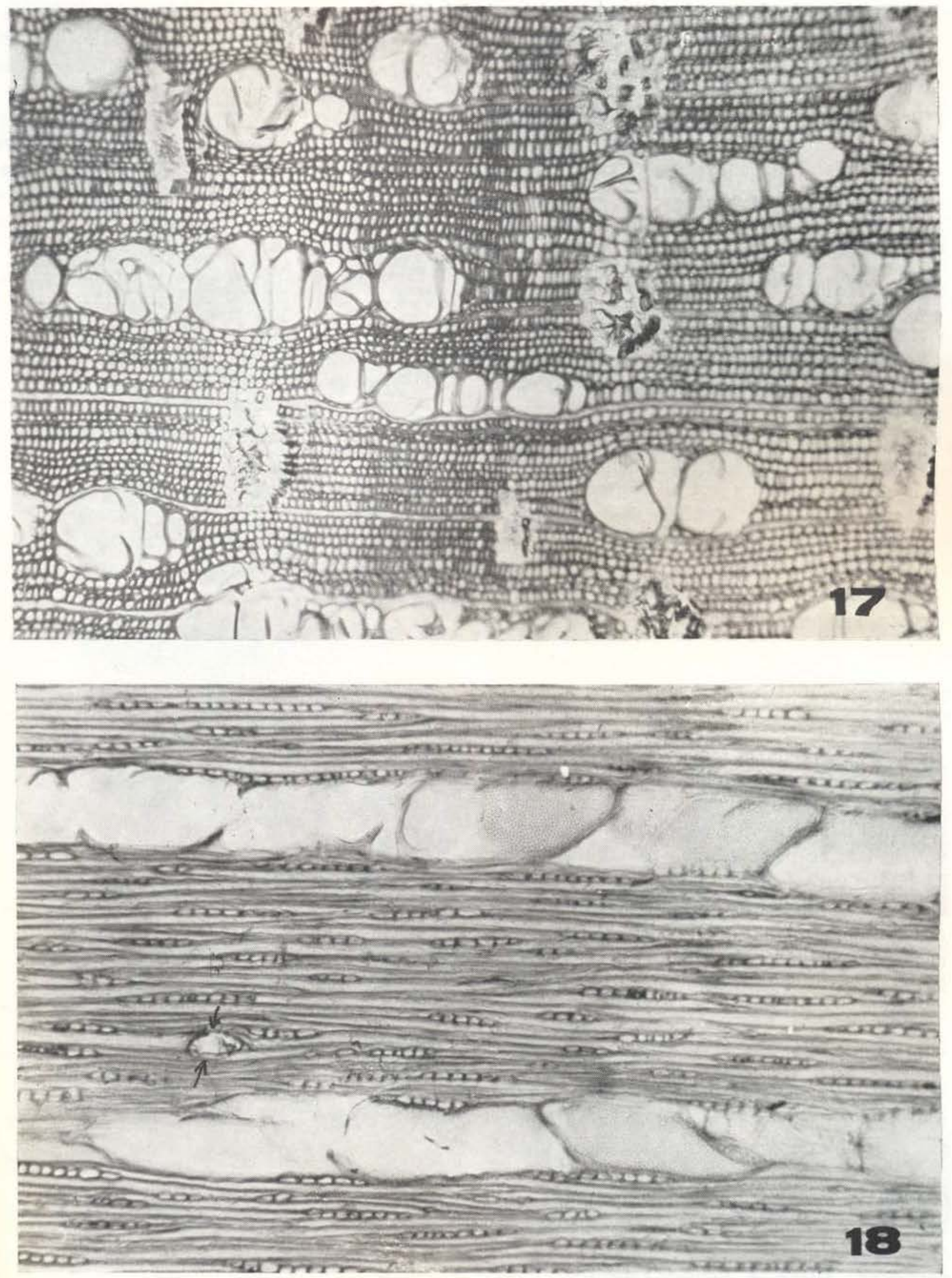

Foto 17) - A. ovata var. excelsa - Madeira : secção transversal, onde se vêem vários cordōes de floema incluso $(100 \mathrm{X})$. Foto 18$)-A$, ovata var, ovata - Madeira : secção tangencial $(100 \mathrm{X})$. 
fundamental com pontuações simples. Aproximadamente na altura, da metade do comprimento do pecíolo, os feixes vasculares bicolaterais, vistos em cortes transversais, se apresentam sob a forma aproximadamente de "V" (Foto 6; fig. 2-e) entre as células medulares, geralmente com paredes espessas lignificadas, ocorrem cordões de floema medular. No parênquima da face adaxial do pecíolo observam-se quatro cordões vasculares.

b) Lâmina foliar - Epiderme abaxial pilosa ou quase glabra; tricomas unicelulares; em vista frontal as células das epidermes abaxial e adaxial apresentam paredes e contornos irregulares. Hipoderme representada por 2-3 camadas de células com forma e tamanho diferentes das células da epiderme adaxial, algumas delas ricas em polifenóis. O parenquima paliçádico $\epsilon$ bastante reduzido, constituído geralmente, de duas camadas de células (por divisões periclinais tardias); enquanto que o parênquima lacunoso é bem mais espesso do que aquele, com tacunas reduzidas ou ausentes em certas regiōes; no parênquima lacunoso são freqüentes células com polifenóis. Em geral, as nervuras mais finas são envolvidas por uma bainha (condutora de Haberlandt) de células de paredes moderadamente espessas, pectocelulósicas. Os feixes vasculares da nervura central, vistas em secção transversal, se apresentam sob a forma de um arco contínuo; as células do parênquima fundamental dessa nervura são freqüentemente esclerosadas; entre as células da porção interna da região vascular ocorrem cordões de floema. Os estômatos ocorrem unicamente na epiderme abaxial, numa média de 416 por $\mathrm{mm}^{2}$; são tipicamente anomocíticos (cruciferos). (Fig. 2: a e Fig. 3: a).

\section{Discussão}

Grãos de pólen - Os grãos de pólen das três variedades de Antonia ovata aqui estudadas são muito semelhantes, apenas, os espécimes de Antonia ovata Pohl var. excelsa Paula possuem grãos de pólen com os subcircular com tendência a "lolangate", enquanto que nas variedades ovata e pilosa, os ora são tipicamente circulares. (Válio \& Salgado-Labouriau, 1954) salientam polimorfismo (oblato e prolato) entre espécimes de Antonia ovata, procedentes de Furnas-Minas Gerais (SP 53145), de Caracarahy, Território do Rio Branco (SP 56835), e de Santa Cruz dos Martires, região do Araguaia (SP 57297). Os espécimes das 3 variedades por nós estudados apresentam polimorfismo, salvo os da variedade pilosa. (Erdtman, 1966) não faz referência sobre polimorfismo em Antonia ova$t a$, talvez ele tenha estudado apenas a variedade pilosa.

Madeira - (Record \& Hess, 1949) afirmam que a madeira de Antonia ovata apresenta estrutura anômala; sem cheiro e sabor; textura média, granulação irregular; raios unisseriados, mas ocorrendo fusiformes, com cordões de floema. Além desses dados, nossos estudos revelaram a presença de oxalato de cálcio no floema da variedade excelsa; fibrotraqueóides e camadas de crescimento, sendo pouco típicas na variedade excelsa. A diferença do número de poros por $\mathrm{mm}^{2}$ entre as variedades pilosa (82 poros) e a variedade excelsa ( 44 poros) é realmen-

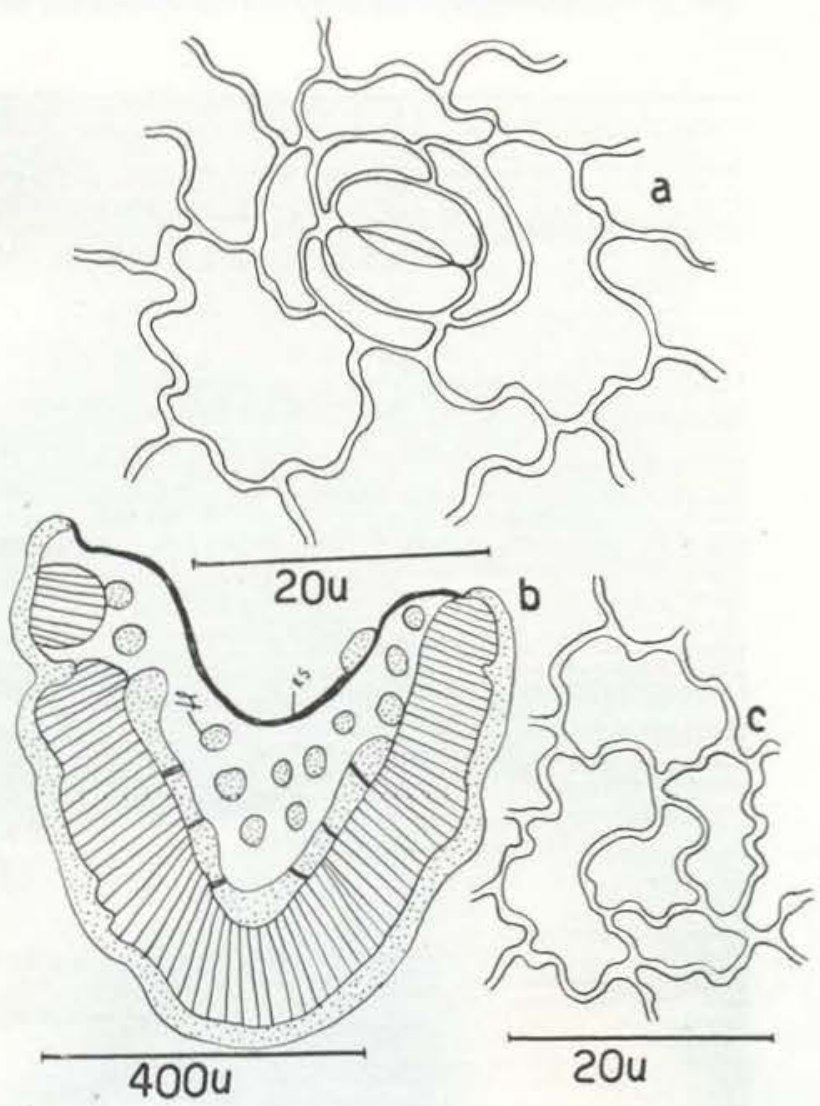

Fig. 3 - a) var. ovata: epiderme abaxial; b) var pilosa: sistema vascular da porção média do pecíolo: c) var. ovata : epiderme adaxial. 


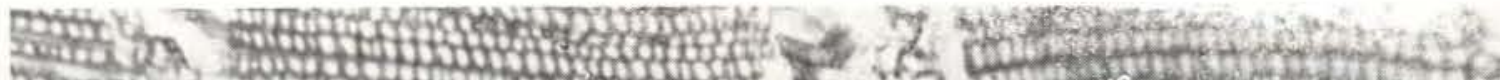

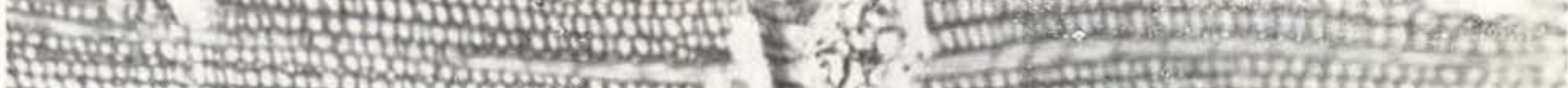

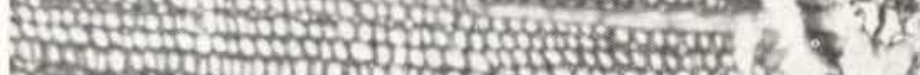
Sevo ftorte the

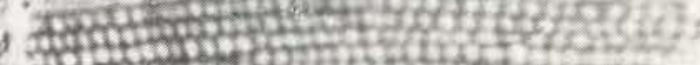

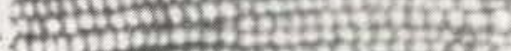

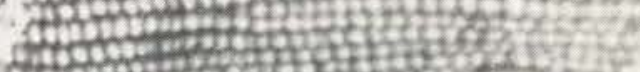
Westo

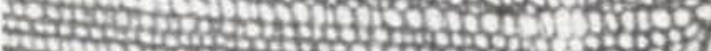
G.0.t.

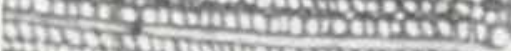
ty

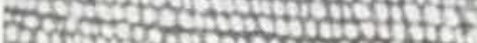

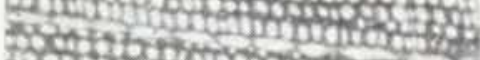

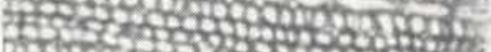

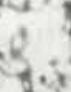

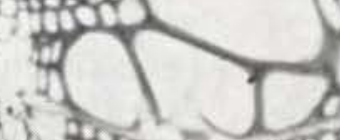

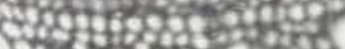

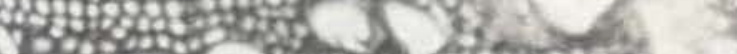

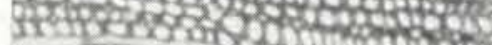
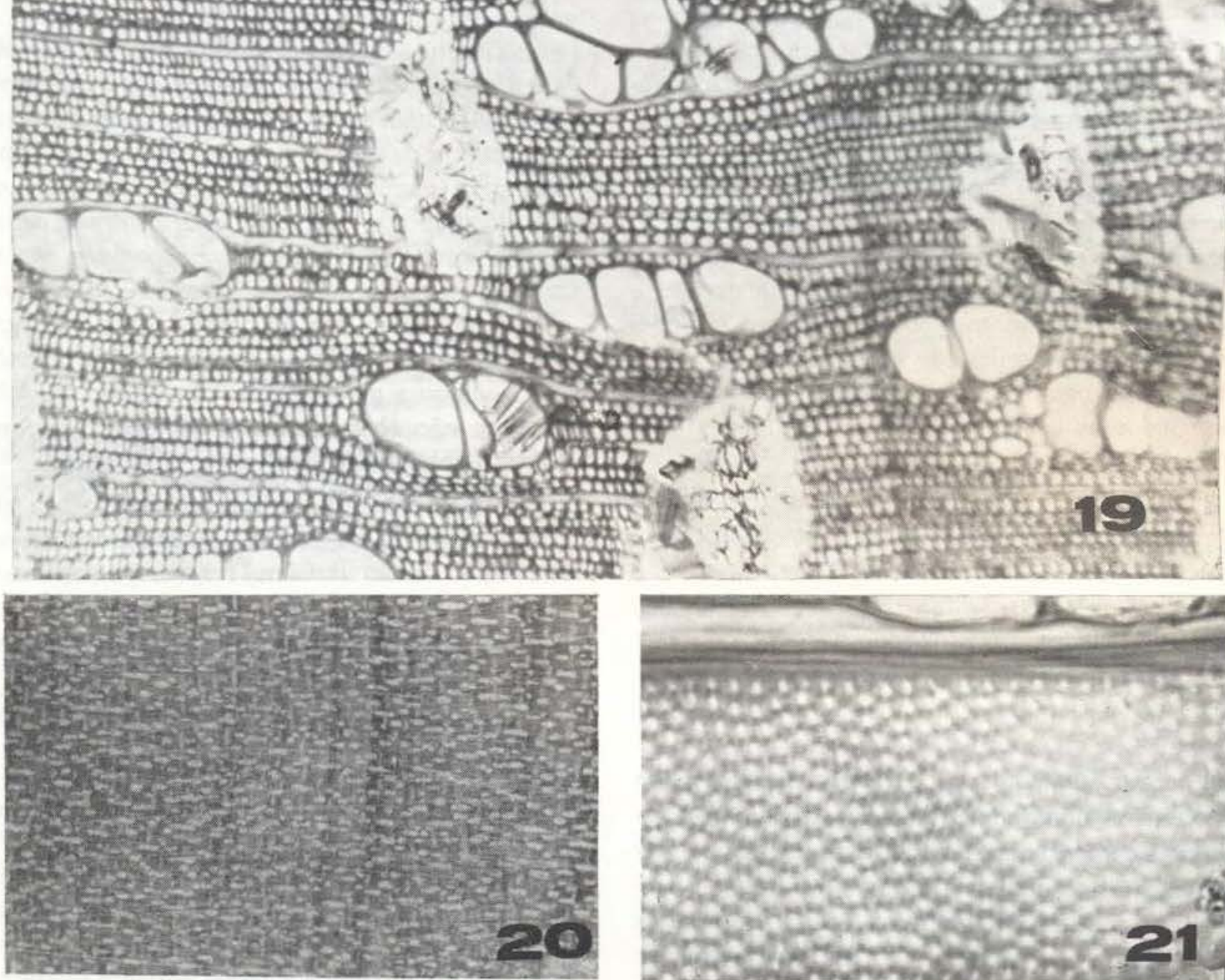

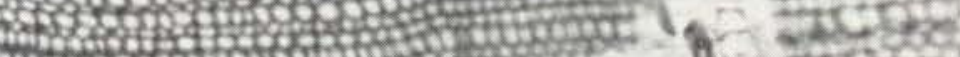

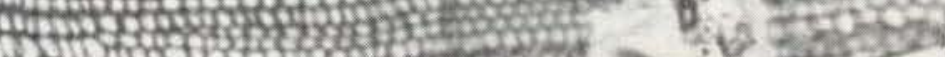
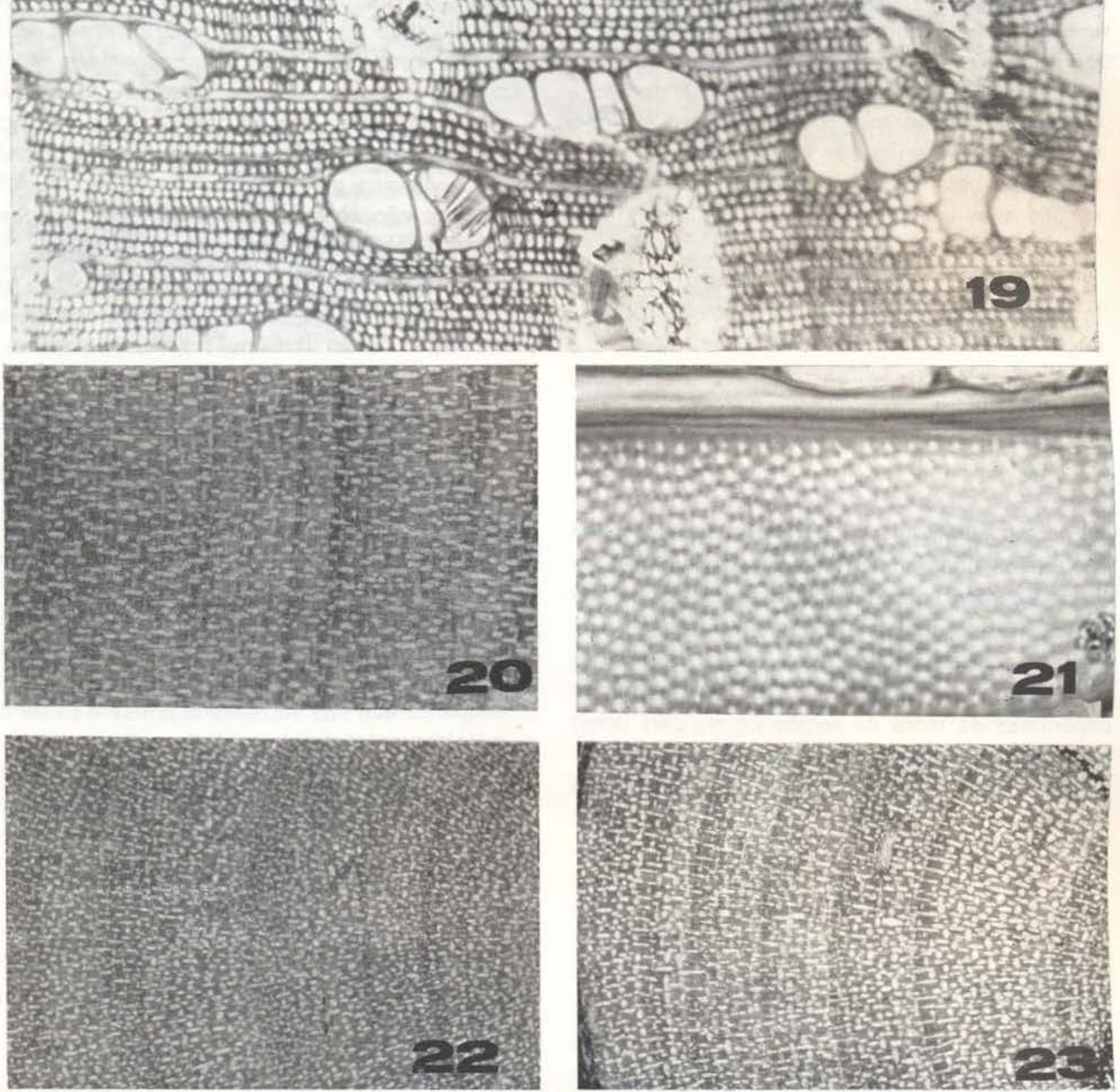

Foto 19) - A. ovata var. ovata - Madeira : seç̧âo transversal $(100 \mathrm{X})$. Foto 20$)-A$. ovata var. excels. - Madeira.: aspecto macroscópico (8X). Foto 21) - A ovata var. excelsa - Madeira.: pontuações intervas. culares $(86 \mathrm{X})$. Foto 22) $-A$. ovata var. ovata - Madeira : aspecto macroscópico (8X.) Foto 23) - A. ova ta var. pilosa - Madeira.: aspecto macroscópico (8X). 
te marcante e mais ainda entre as variedades ovata (30 poros) e a pilosa. Os raios, da variedade ovata, são mais numerosos, mais altos do que os das variedades excelsa e pilosa. É realmente notável o número de cordões de floema incluso por $\mathrm{mm}^{2}$, verificado na variedade pilosa (vide quadro comparativo).

Lâmina foliar - As epidermes dos espécimes das variedades excelsa e pilosa são pilosas; em vista frontal apresentam células com paredes e contornos regulares, enquanto que, na variedade, ovata as células de ambas as epidermes apresentam contornos sinuosos (Fig. 3 , a e c). O número de estômatos por $\mathrm{mm}^{2}$, das variedades ovata e pilosa é da ordem de 506 e 440 , respectivamente, enquanto que na variedade excelsa é da ordem de 416. A estrutura anatômica do pecíolo e do mesófilo é semelhante em todos os espécimes por nós estudados (Fig. 3-b e Foto 6).

Pelo que vimos, Antonia ovata var. pilosa tem mais afinidade estrutural com a variedade excelsa do que com a variedade ovata. As diferenças mais evidentes estão entre aquelas duas variedades e a variedade ovata. As características exclusivas de Antonia ovata var. ex. celsa são: habitat - da mata, altura - árvore de até $30 \mathrm{~m}$, diâmetro - de até $1 \mathrm{~m}$, grão de pó. len com os tendendo a "Iolangate", presença de idioblastos contendo drusas de oxalato de cálcio no floema incluso, madeira de cor bege e ausência da fluorescência da madeira quando submetida a luz ultra-violeta. Essas diferenças ainda são insuficientes para se considerar os espécimes da mata da regiaão do rio Jarí como sendo uma espécie nova, que constituiria com Antonia ovata um par vicariante. A relação cerrado-mata e árvore alta-baixa é um critério válido até certo ponto. Vejamos Salvertia convallariodora St. Hil., espécie típica de cerrado, nas proximidades de mata úmida, cresce muito mais em altura e em diâmetro do que nos cerrados (Paula, 1969) já observamos Curatella americana L., em solo permanentemente úmido (em margens de "lagos", em Porto Platon - T. F. do Amapá) bastante alta e grossa em comparação com espécimes do cerrado típico. (Labouriau et alii, 1964) afirmam que plantas de Caryocar brasiliensis de experimentos realizados pelo
Professor E. P. Heringer, em Paraopeba, Estado de Minas Gerais, em área de cerrado, que foram irrigadas nas duas primeiras estações secas que se seguiram ao plantio, desenvolveram-se de maneira drasticamente muito mais rápida e vigorosa que as testemunhas năo irrigadas plantadas no mesmo solo e na mesma data.

Rizzini (1963) nomeia 49 pares Vicariantes para o Brasil. A pouca volubilidade de caracteres entre os espécimes de Antonia ovata dos cerrados e da mata do rio Jarí levou-nos a considerar os espécimes da mata como sendo uma variedade nova: Antonia ovata Pohl var. excelsa Paula, constituindo vicariança com as varieda. des do cerrado; sugere, também, estudos em vários aspectos dos 49 pares vicariantes acima mencionados, inclusive anatômico, cromosômico, químico e palinológico, no sentido de definir melhor, não sòmente as 98 espécies em apreço como também o conceito de Vicariança.

Finalmente, os nossos resultados não afastam a hipótese de serem os espécimes da mata da região do rio Jarí uma nova espécie, levando em conta que ainda faltam ser estudados : raíz, cromosomas, quimicamente os demais órgãos e germinação e suas plântulas.

\section{ConClusões}

Do nosso estudo, destacamos os dados mais expressivos seguintes: a) os grãos de pólen de 2 variedades de Antonia ovata apresentam polimorfismo; os da variedade excelsa é subcircular, com tendência para "lolangate", enquanto que nas variedades pilosa e ovata o os é tipicamente circular. b) A madeira apresenta características, notadamente as numéricas dos elementos componentes do lenho secundário capazes de ajudarem a separação de 3 variedades, em apreço (vide quadro comparativo). c) $\mathrm{O}$ caule é rico em células taníferas e mucilaginíferas; os feixes vasculares são bicolaterais; a região vascular, vista em secção transversal, tem forma semelhante a da "Cruz de Malta": o rastro foliar é constituído de 2 feixes vasculares e o nó foliar é bilacunar. d) A folha de Antonia ovata apresenta estrutura de planta higrófila. Provavelmente Antonia, gênero isolado seja um gênero amazônico, ocorrendo também nos cerrados extra-amazônicos. e) Considera. 
mos os espécimes da mata da regiâo do rio Jarí. como sendo uma nova variedade: Antonia ovata Pohl var. excelsa Paula.

\section{Agradecimentos}

Agradecemos aos Senhores Dr. Jorge Fontella Pereira, do Jardim Botânico do Rio de Ja. neiro, Dr. F. R. Milanez, da Universidade Esta dual de Campinas-SP, Dr. Paulo B. Cavalcante do Museu Goeldi, Dr. Robert Goodlan, Dr. F. G Labouriau, Dr. Ezechias Heringer, da Universida. de de Brasília e Dr. Byron W. Albuquerque, do INPA, a colaboração que nos foi prestada para a execução deste trabalho.

\section{SUMMARY}

In this paper the author studies extern morpho. logical, palinological and anatomical aspects, aiming to put an end to the doubts in the taxonomic studies of the specimens of Antonia ovata Pohl (or aiming make clear the taxonomy of the specimens of Anto. nia ovata.

Specimens of Antonia ovata from the woods of the region of Jarí river (Amazônia) are considered by the author as a new variety. With its description, the number of varieties of Antonia ovata rose to three: pilosa, ovata and excelsa (new variety).

The extern morphological aspect is found among the individuals from three habitats : "cerrados" of Amazônia, Brasil Central and forest of the region Jari river. The identification of the three varieties is based on the following characteristic. Presence or lack of hairs on the leaves and branches; microscopic structure of wood (see comparative table); height and diameter of the specimens; and finally the habitat.

Pollen grains of these two varieties excelsa and ovata present polymorphism. The leaf of that species has structure of a higrophyllous plants. The stem is rich in mucilaginous cells; vascular bundles are bicoliateral; the leafknot is bilacunar, and the trace is formed by two vascular bundles.

\section{BIBLIORRAFIA CITADA}

CANDOlle, A. P. DE

1845 - Prodromus systematis naturalis regni vegetabilis. Paris. 17 v., v. 9: 1-573.

ERdtMan, G.

1966 - Pollen morphology and taxonomy, angiosperms. New York and London, Hafner Publ. comp. 553 p., 261 fig. 1 est.

Labouriau, L. G. et alII

1964 - Sôbre o sistema reprodutivo de plantas dos cerrados. I. Anais Acad, Bras. Cienc., Rio de Janeiro, 36: 449-464. 59 fig. 2 tab.

Paula, J. E. DE

1969 - Estudos sôbre Vochysiaceae - V. Contribuição para o conhecimento eco-morfológico de Salvertia convallariodora St, Hil. In : Anais do XX Congresso Nacional de Botânica da Soc. Bot. do Brasil, Goiânia. p. : 243-258 13 fig., 5 quad.

POHL, J. B, E.

1828/29 - Plantarum brasiliae, 2(1) : 13-15, pl. 109 Progel, A.

1860/68 - "Loganiaceae". In : Martius, C. F. Ph. de - Flora Brasiliensis, 6(1): 250-299, 17 tab. (67-82),

RECORD, S. J. \& HEss, R. E.

1949 - Timbers of the new world. New Haven, Yale University. $\mathrm{xV}+640$ p., 58 est. 8 map.

RIZZINI, C. T.

1963 - Flora do cerrado. In : Simpósio sôbre o cerrado, São Paulo. p. : $125-176,8$ fotos, 1 est.

Salgado-Labouriau, M. L.

1561 - Palinologia, fundamentos, técnica e algumas perspectivas. Rev. Bras. Geogr., Rio de Ja neiro, 23(4) : 695-717, 10 fig.

1966 - Palinologia dos cerrados. Anais Acad, Bras. Cienc., Rio de Janeiro, Supl. 38: 187-205, 23 fig., 4 tab.

Válio, I. F. \& Salgado-labouriau, M. L.

1964 - Pollen grains of plants of the "cerrado" VII. Labiatae subfamily Sunilacoideat and Loganiaceae. Rev, Bras. Biol., Rio de Janeiro, 24(2): 120-126, 21 fig. 


\begin{tabular}{|c|c|c|c|c|c|}
\hline \multirow{2}{*}{ DIFERENCIACOES } & \multirow{2}{*}{\multicolumn{2}{|c|}{ CARACTERES COMUNS }} & \multicolumn{3}{|c|}{ CARACTERES DIFERENCIAIS } \\
\hline & & & $\begin{array}{r}\text { Antonia ovata var. } \\
\text { excelsa }\end{array}$ & $\begin{array}{l}\text { Antonia ovata var } \\
\text { pilosa }\end{array}$ & $\begin{array}{l}\text { Antonia ovata var } \\
\text { ovata }\end{array}$ \\
\hline \multirow{2}{*}{ POROS } & $\begin{array}{l}\text { Número por } \\
\mathrm{mm}^{2} \text { média }\end{array}$ & $\longrightarrow$ & $\begin{array}{l}\text { 44, numerosíssimos. } \\
\text { variando entre } 37 \mathrm{e} \\
52 \text {. }\end{array}$ & $\begin{array}{l}82 \text {, extremamente } \\
\text { numerosos, varian- } \\
\text { do entre } 73 \text { e } 88 \text {. }\end{array}$ & $\begin{array}{l}30 \text {, numerosos, va. } \\
\text { riando entre } 26 \text { e } 33\end{array}$ \\
\hline & $\begin{array}{l}\text { diâmetro } \\
\text { radial-média }\end{array}$ & $\longrightarrow$ & $\begin{array}{l}59 \mu \text {, pequenos, va- } \\
\text { riando entre } 25 \mathrm{e} \\
115 .\end{array}$ & $\begin{array}{l}33 \mu \text {, muito peque- } \\
\text { nos, variando entre } \\
15 \text { e } 60 .\end{array}$ & $\begin{array}{l}65 \mu \text {, pequenos, va } \\
\text { riando entre } 26 \text { e } 33\end{array}$ \\
\hline $\begin{array}{l}\text { ELEMENTOS } \\
\text { VASCULARES }\end{array}$ & $\begin{array}{l}\text { comprimento } \\
\text { em } \mu\end{array}$ & $\begin{array}{l}\text { área de perfura } \\
\text { ção simples, par- } \\
\text { cial; curtos }\end{array}$ & $\begin{array}{l}0,5 \mathrm{~mm} \text {, variando en } \\
\text { tre } 0,3 \text { e } 0,78 \text {. }\end{array}$ & $\begin{array}{l}0,5 \mathrm{~mm} \text {, variando en- } \\
\text { tre } 0,38 \text { e } 0,64\end{array}$ & $\begin{array}{l}0,56 \mathrm{~mm} \text {, variando } \\
\text { entre } 0,3 \text { e } 0,76 .\end{array}$ \\
\hline \multirow{2}{*}{ RAIOS } & $\begin{array}{l}\text { número por } \\
\text { mm-média }\end{array}$ & unisseriados & $\begin{array}{l}10 \text { por mm, nume- } \\
\text { rosos, variando en- } \\
\text { tre } 7 \text { e } 13 \text {. }\end{array}$ & $\begin{array}{l}10 \text { por mm, nume- } \\
\text { rosos, variando en- } \\
\text { tre } 7 \text { e } 13 \text {. }\end{array}$ & $\begin{array}{l}14 \text { por } \mathrm{mm} \text {, muitc } \\
\text { numerosos, varian } \\
\text { do entre } 12 \text { e } 16 .\end{array}$ \\
\hline & $\begin{array}{l}\text { altura } \\
\text { média }\end{array}$ & $\begin{array}{l}\text { extremamente } \\
\text { baixos }\end{array}$ & $\begin{array}{l}95 \mu \text {, variando en. } \\
\text { tre } 32 \text { e } 196 .\end{array}$ & $\begin{array}{l}81 \mu \text {, variando entre } \\
35 \text { e } 163 .\end{array}$ & $\begin{array}{l}140 \mu \text {, variando en } \\
\text { tre } 48 \text { e } 278 .\end{array}$ \\
\hline \multirow{2}{*}{ FIBRAS } & espessura & muito delgadas & - & - & $\longrightarrow$ \\
\hline & $\begin{array}{l}\text { comprimento } \\
\text { média }\end{array}$ & $\begin{array}{l}\text { muito } \\
\text { curtas }\end{array}$ & $\begin{array}{l}095 \mathrm{~mm}, \quad \text { variando } \\
\text { entre } 0,5 \text { e } 0,8\end{array}$ & $\begin{array}{l}0,66 \mathrm{~mm}, \quad \text { variandc } \\
\text { entre } 0,4 \text { e } 0,8 \text {. }\end{array}$ & $\begin{array}{l}0,9 \mathrm{~mm} \text {, variando en } \\
\text { tre } 0,7 \text { e } 1 \mathrm{~mm} \text {. }\end{array}$ \\
\hline PARENQUIMA & - & $\begin{array}{l}\text { geralmente } \\
\text { ausente }\end{array}$ & - & - & $\longrightarrow$ \\
\hline $\begin{array}{l}\text { FLOEMA } \\
\text { INCLUSO }\end{array}$ & $\begin{array}{l}\text { Número de } \\
\text { cordôes por } \\
\text { mm²-média }\end{array}$ & - & $\begin{array}{l}\text { 7, variando entre } \\
3 \text { e } 7 \text {. }\end{array}$ & $\begin{array}{l}23 \text {, variando entre } \\
19 \text { e } 28\end{array}$ & $\begin{array}{l}5 \text {, variando entre } 2 \\
\text { e } 7 .\end{array}$ \\
\hline $\begin{array}{l}\text { FIBROTRA- } \\
\text { QUEOIDES }\end{array}$ & $\begin{array}{l}\text { comprimento } \\
\text { média }\end{array}$ & - & $0,5 \mathrm{~mm}$; escassos. & $0,56 \mathrm{~mm} ;$ frequentes & $0,5 \mathrm{~mm}$; escassos. \\
\hline
\end{tabular}

